\title{
The Effect of Newspaper Coverage and Political Pressure on Wildfire Suppression Costs
}

\author{
GEOFFREY H. DONOVAN \\ USDA Forest Service, PNW Research Station, Portland, Oregon, USA
}

JEFFREY P. PRESTEMON

USDA Forest Service, Southern Research Station, Research Triangle

Park, North Carolina, USA

KRISTA GEBERT

USDA Forest Service, Rocky Mountain Research Station, Missoula, Montana, USA

\begin{abstract}
Controlling wildfire suppression expenditures has become a major public policy concern in the United States. However, most policy remedies have focused on the biophysical determinants of suppression costs: fuel loads and weather, for example. We show that two non-biophysical variables - newspaper coverage and political pressure-have a significant effect on wildfire suppression costs. Hausman tests showed that newspaper coverage and fire size were endogenous, so regression models were estimated using two-stage least squares. We suggest a number of non-biophysical policy remedies that may be able to reduce wildfire suppression expenditures more cost-effectively than traditional biophysical remedies such as fuel management.
\end{abstract}

Keywords endogeneity, forestry, media coverage, political influence

Wildfire suppression costs in the United States have been trending upward since the mid 1980s (Calkin et al. 2005; Prestemon et al. 2008; Abt et al. 2009), and controlling these costs has become a major public-policy concern. Most proposed remedies implicitly treat wildfire suppression costs as a function of biophysical variables: weather, vegetation, topography, and resources at risk, for example. However, this view neglects the human dimension of wildfire costs. Although weather and vegetation may influence the choices made by fire managers, it is still managers who make all suppression decisions, and non-biophysical factors may play an important role in this decision-making process.

To provide some insight into the importance of biophysical and non-biophysical factors, we estimate a model of wildfire costs that includes biophysical variables as well as two variables that exert no biophysical influence: newspaper coverage and

This article not subject to U.S. copyright law.

Received 4 August 2009; accepted 6 January 2010.

Address correspondence to Geoffrey H. Donovan, USDA Forest Service, PNW Research Station, 620 SW Main, Suite 400, Portland, OR 97205, USA. E-mail: gdonovan@fs.fed.us 
political influence. It is not our intention to present comprehensive models of the effects of newspaper coverage and political pressure on wildfire costs. Indeed, because neither can be manipulated to reduce wildfire costs, we are only interested in newspaper coverage and political pressure as examples of non-biophysical variables. If newspaper coverage or political pressure increases wildfire costs, then it is possible that non-biophysical policy instruments may be able to reduce suppression costs. Identifying effective, non-biophysical ways of reducing suppression costs is important because although biophysical approaches such as fuel treatment can effectively reduce wildfire damages (Mercer et al. 2007), budget constraints and other logistical difficulties mean that wildfire management may not be the only, or the most effective, means of reducing wildfire suppression costs at a national level (Donovan and Brown 2007).

\section{Literature Review}

Although much has been written about the possible causes of increased wildfire activity in recent years, relatively few studies have been able to identify variables that affect wildfire suppression costs. Wildfire suppression expenditures and area burned are highly correlated, and in the past two decades, both have exhibited increases in magnitude and year-to-year variation (Calkin et al. 2005). This increase in area burned by wildfire has been attributed to drought, rising temperatures, earlier melting of snow pack, and fuel buildups due to past wildfire suppression (Arno and Brown 1991; Calkin et al. 2005; Collins et al. 2006; Westerling et al. 2006; Kitzberger et al. 2007). More recently, Prestemon et al. (2008), in a study designed to provide forecasts of annual U.S. Forest Service (USFS) suppression expenditures, found evidence of an upward trend in annual Forest Service suppression costs over the past three decades; this is separate from the effects of observed changes in climate and weather patterns.

Several studies have examined suppression costs at the individual wildfire, as opposed to national or regional, scale. Increased development in the wildand-urban interface has been suggested as an influence on suppression expenditures (NAPA 2002; Canton-Thompson et al. 2006; OIG 2006), and several studies have attempted to verify this assertion empirically. Donovan et al. (2004) used regression analysis to look at the effect of housing density on suppression expenditures using a sample of 58 wildfires that occurred in Oregon and Washington in 2002, but housing density failed to show up as a significant predictor of costs. Using a larger data set, Gebert et al. (2007) estimated a regression model of suppression costs in the Western United States (USFS Regions 1 through 6). They found that higher home values within 20 miles of a wildfire ignition increased suppression expenditures. Some of the other variables that influenced suppression costs were extreme fire behavior, drought conditions, wildfire intensity levels, and energy release component. Liang et al. (2008) studied USFS wildfire suppression expenditures for 100 large wildfires occurring in the Northern Region (R1) of the USFS. They found wildfire size and the percentage of private land within the burned area had a strong effect on suppression expenditures.

All the studies described so far fail to explain a significant portion of the variation in suppression expenditures, perhaps because they didn't fully consider the incentives faced by managers making wildfire suppression decisions. One study that did examine the human component of wildfire suppression costs was by 
Canton-Thompson et al. (2006). This study described interviews with incident command teams designed to identify important determinants of suppression costs. Two factors mentioned repeatedly by interviewees were (1) concern about the negative personal consequences of adverse wildfire outcomes and (2) social or political influences on suppression strategies. Both of these factors may encourage managers to use more firefighting resources. In the case of factor (2), despite pressure at the national level to reduce suppression costs, local politicians, when faced with wildfires in their own district, often exert pressure on the teams to use resources, strategies, or tactics that interviewees suggested would not have normally been used and that, in many cases, they knew would be ineffective. Anecdotal evidence of the effect of political pressure on suppression costs can also be found in the popular press. For example, in a story in the Sacramento Bee (Knudson 2006), a retired Forest Service fire and aviation manager recounted pressure from members of Congress to use unnecessary aerial fire-retardant drops, and, in one case, to call out the military.

The effect of media coverage on hazard management has been formalized in behavioral science theory under the broad umbrella of the "social amplification of risk" (Kasperson et al. 1988; Raude et al. 2004; Vilella-Villa and Costa-Font 2008). In this framework, individual and institutional decisions about hazards can be distorted by the media and other forms of public and private communications. In consequence, decision makers may manage hazards in ways that are not economically efficient. In addition, media coverage can encourage well-documented human tendencies to rate low-probability high-consequence events as more severe than higher probability low-consequence events of the same expected value (Kahneman and Tversky 1979). In the context of wildfire suppression, then, media coverage may increase managers' concerns about the personal consequences of adverse wildfire outcomes.

Several studies have examined how the media covers forest management issues. Bengston et al. (2004) found that between 1980 and 2001, media coverage reflected a shift in forest values from anthropocentric to biocentric. Shindler et al. (1996) demonstrated that people get most of their information about federal forest policy from the media. At the time of Shindler's study, newspapers were a particularly important source of information, although that may have declined over time.

Other studies have examined the effect of the media on the behavior of individuals and firms. Of particular relevance to this study is research that shows that media coverage both reflects and shapes public opinion (Fan 1988); media coverage is generally viewed as more credible than corporate communications (Bond and Kirshenbaum 1998); people give more weight to negative information (Mizerski 1982); the actions of experts in a field can be shaped by media coverage (Raude et al. 2004); and the media prefer to report bad rather than good news (Dennis and Merrill 1996).

\section{Theoretical Model}

The most efficient level of wildfire suppression minimizes the sum of all wildfire-related costs and damages. The cost plus net value change $(\mathrm{C}+\mathrm{NVC})$ model expresses this principle mathematically (Donovan and Rideout 2003):

$$
M I N C+N V C=W^{P} \bar{P}+W^{S} S+N V C(\bar{P}, S)
$$


where $W^{P}$ is the per-unit cost of presuppression, $\bar{P}$ is the fixed level of presuppression, ${ }^{1} W^{S}$ is the per-unit cost of suppression, $S$ is suppression, and $N V C$ is the net wildfire damages (also referred to as net value change). Note that variables on the outside of parentheses are a function of variables inside parentheses. For example, net wildfire damages are a function of the amount of presuppression and suppression employed.

Net wildfire damages include the net effect (typically negative) of a wildfire on natural and built resources. We hypothesize that this model doesn't consider one potentially important component of wildfire suppression: costs uniquely borne by the fire manager (and not by fire management agencies themselves). These costs include adverse career consequences and personal lawsuits, for example. The $\mathrm{C}+\mathrm{NVC}$ model can be rewritten to include this category of costs:

$$
\begin{aligned}
& M I N C+N V C+M C=W^{P} \bar{P}+W^{S} S+N V C(\bar{P}, S) \\
& +M C[N V C, N E W(N V C), P O L(N V C, N E W)]
\end{aligned}
$$

where $M C$ is manager costs, $N E W$ is newspaper coverage, and $P O L$ is political influence.

Note that newspaper coverage and political influence are not independent variables. Rather, both are a function of $N V C$. Therefore, newspaper coverage and political influence can be thought of as simply amplifying the effect of $N V C$ on manager costs. The corollary of this is that increasing suppression expenditures will decrease $N V C$, newspaper coverage, and political influence.

We are not suggesting that this model fully accounts for all the possible influences on managers' decision making. Rather, we are simply extending the $C+N V C$ model to accommodate two important influences on managers' behavior identified by previous research. In addition, the model implies a testable hypothesis: Newspaper coverage and political influence increase suppression costs.

\section{Methods}

\section{Data}

We use a slightly modified version of the model presented in Gebert et al. (2007) and a subset of the data set used in that analysis (a subset of the data was used because collecting data on newspaper coverage was time-intensive). The data set we used consists of variables describing 523 large $(100+$ acres) wildfires occurring from 2003 to 2007 in the western United States. The data set is restricted to wildfires where the USFS was the recorded protection agency or the majority of the acres burned were under USFS jurisdiction and for which reliable cost data were available. Included in the data set is the following wildfire-specific information: (1) suppression expenditure data from all involved federal agencies, ${ }^{2}(2)$ wildfire characteristic information from the Forest Service's fire occurrence database system (the National Interagency Fire Management Integrated Database or NIFMID), and (3) variables calculated from the latitude and longitude of the wildfire ignition point (Table 1). Two variables used in the original Gebert et al. (2007) study were not included in our analysis - detection delay (the time from wildfire start to discovery) and initial suppression strategy. Subsequent discussions with agency personnel indicated that these variables were of questionable quality, so we dropped them from this analysis. 
Table 1. Newspaper coverage variables

\begin{tabular}{|c|c|}
\hline Variable & Definition \\
\hline STORY_30 K & $\begin{array}{l}1 \text { if there are any newspaper stories about a fire in the nearest } \\
\text { city with a population of } 30,000 \text { to } 99,999,0 \text { otherwise }\end{array}$ \\
\hline WORDS_30 K & $\begin{array}{l}\text { Total number of words written about a fire in the nearest city } \\
\text { with a population of } 30,000 \text { to } 99,999\end{array}$ \\
\hline FRONT_30 K & $\begin{array}{l}1 \text { if there are front-page stories in the nearest city with a } \\
\text { population of } 30,000 \text { to } 99,999,0 \text { otherwise }\end{array}$ \\
\hline NUMBER_30 K & $\begin{array}{l}\text { Number of stories in the nearest city with a population of } \\
30,000 \text { to } 99,999\end{array}$ \\
\hline STORY_100 K & $\begin{array}{l}1 \text { if there are any newspaper stories about a fire in the nearest } \\
\text { city with a population of } 100,000 \text { to } 249,999,0 \text { otherwise }\end{array}$ \\
\hline WORDS_100K & $\begin{array}{l}\text { Total number of words written about a fire in the nearest city } \\
\text { with a population of } 100,000 \text { to } 249,999\end{array}$ \\
\hline FRONT_100 K & $\begin{array}{l}1 \text { if there are front-page stories in the nearest city with a } \\
\text { population of } 100,000 \text { to } 249,999,0 \text { otherwise }\end{array}$ \\
\hline NUMBER_100 K & $\begin{array}{l}\text { Number of stories in the nearest city with a population of } \\
100,000 \text { to } 249,999\end{array}$ \\
\hline STORY_250 K & $\begin{array}{l}1 \text { if there are any newspaper stories about a fire in the nearest } \\
\text { city with a population over } 250,000,0 \text { otherwise }\end{array}$ \\
\hline WORDS_250 K & $\begin{array}{l}\text { Total number of words written about a fire in the nearest city } \\
\text { with a population of over } 250,000\end{array}$ \\
\hline FRONT_250 K & $\begin{array}{l}1 \text { if there are front-page stories in the nearest city with a } \\
\text { population over } 250,000,0 \text { otherwise }\end{array}$ \\
\hline NUMBER_250 K & $\begin{array}{l}\text { Number of stories in the nearest city with a population of over } \\
250,000\end{array}$ \\
\hline
\end{tabular}

To test for the effect of newspaper coverage on suppression expenditures, for each wildfire, we determined the closest ${ }^{3}$ cities with the following population ranges: (1) $250,000+$, (2) 100,000 to 249,999 , (3) 30,000 to 99,999 . We then searched ${ }^{4}$ for newspaper articles with the word "fire" or "wildfire" in the story that were published in each city while a wildfire was uncontained. If an article was about the wildfire in question, we recorded the number of words in the article and whether or not it was on the front page (Table 2).

We did not consider the effect of other types of media coverage, such as television, on suppression, because it is not the goal of this study to present a comprehensive model of the effects of media coverage on suppression costs. Rather, the purpose of this study is to determine whether non-biophysical variables influence wildfire suppression costs, and newspaper coverage is simply an example of a non-biophysical variable. Of course, other forms of media may also affect wildfire suppression costs. ${ }^{5}$ However, this is a separate question that we leave to future studies.

Directly quantifying political influence would be extremely difficult even if we knew what type of contacts a fire manager had with politicians and their staff. In addition, any variable describing political contacts would likely be endogenous (i.e., co-determined) with wildfire suppression costs. Therefore, we considered what 
Table 2. Biophysical variable definitions

\begin{tabular}{|c|c|}
\hline Variable & Definition \\
\hline Cosine of aspect & Cosine of aspect in 45-degree increments \\
\hline Sine of aspect & Sine of aspect in 45-degree increments \\
\hline Slope & Percentage slope \\
\hline Elevation & Elevation in feet \\
\hline Timber ignition point & 1 if timber, 0 otherwise \\
\hline Grass ignition point & 1 if grass, 0 otherwise \\
\hline Brush ignition point & 1 if brush, 0 otherwise \\
\hline Slash ignition point & 1 if slash, 0 otherwise \\
\hline FIL2 & 1 if fire intensity level 2,0 otherwise \\
\hline FIL3 & 1 if fire intensity level 3,0 otherwise \\
\hline FIL4 & 1 if fire intensity level 4,0 otherwise \\
\hline FIL5 & 1 if fire intensity level 5,0 otherwise \\
\hline FIL6 & 1 if fire intensity level 6,0 otherwise \\
\hline DIST_ALL & Distance to nearest census designated place in miles \\
\hline Total house value 5 miles & Housing value in 5 -mile radius \\
\hline Total house value 20 miles & Housing value in 20 -mile radius \\
\hline Wilderness fire & 1 if ignition is in a wilderness area, 0 otherwise \\
\hline IRA & $\begin{array}{l}1 \text { if ignition is in an inventoried roadless area, } 0 \\
\text { otherwise }\end{array}$ \\
\hline SDA & 1 if ignition is in a special designated area, 0 otherwise \\
\hline REG_2 & 1 if in USFS Region 2,0 otherwise \\
\hline REG_3 & 1 if in USFS Region 3, 0 otherwise \\
\hline REG_4 & 1 if in USFS Region 4,0 otherwise \\
\hline REG_5 & 1 if in USFS Region 5, 0 otherwise \\
\hline REG_6 & 1 if in USFS Region 6,0 otherwise \\
\hline $\mathrm{ERC}$ & Energy release component \\
\hline Fire size & Fire size in acres \\
\hline
\end{tabular}

Note. All variables are measured at a fire's ignition point.

variables would be suitable instruments ${ }^{6}$ for political contacts. We hypothesized that, all else equal, more powerful politicians would have a greater impact on wildfire costs. A call from a freshman member of Congress would likely have less effect than a call from the chairman of the Appropriations Committee, for example. Table 3 lists the political-influence variables we collected for each wildfire.

\section{Model Estimation}

Unlike the biophysical variables in the Gebert et al. (2007) original model, newspaper coverage and suppression costs may be endogenous: Newspaper coverage may increase suppression costs, but wildfires with higher suppression costs may attract more media attention. In addition, fire size and suppression costs may be endogenous. Therefore, we estimated model coefficients using two-stage least squares (2SLS), which required us to use instruments for newspaper coverage and fire size. ${ }^{7}$ 
Table 3. Political-influence variables

Congressional Representative: years in office

Senator 1: years in office

Senator 2: years in office

Congressional Representative: party in the majority $(1,0)$

Senator 1: party in the majority $(1,0)$

Senator 2: party in the majority $(1,0)$

Congressional Representative: number of committee chairmanships held

Senator 1: number of committee chairmanships held

Senator 2: number of committee chairmanships held

Congressional Representative: member of Interior, Environment, and Related Agencies Subcommittee

Senator 1: member of Interior, Environment, and Related Agencies Subcommittee

Senator 2: member of Interior, Environment, and Related Agencies Subcommittee

Congressional Representative: member of National Parks, Forests, and Public

Lands Subcommittees

Senator 1: member of National Parks, Forests, and Public Lands Subcommittees Senator 2: member of national parks, forests, and public Lands Subcommittees

Congressional Representative: member of the Senate Appropriations Committee $(1,0)$

Senator 1: member of the Senate Appropriations Committee $(1,0)$

Senator 2: member of the Senate Appropriations Committee $(1,0)$

Congressional Representative: member of the House natural resources Committee

Senator 1: member of the Senate Energy and Natural Resources Committee

Senator 2: member of the Senate Energy and Natural Resources Committee

Note. Congressional district is based on ignition point; years of service and committee chairmanship are based on ignition date.

For newspaper coverage, we used distance from the city where a story was published to the wildfire's point of ignition as an instrument. Our rationale was that the farther a fire is from a city, the less likely it is to receive newspaper coverage.

We used an additional two instruments to explain variation in both newspaper coverage and fire size. First, we used a year variable (YEAR) to capture a time trend. We hypothesized that overall newspaper coverage - not just coverage of wildfiresmay be declining over time as newspapers are forced to cut costs; certainly, paid circulation has been steadily declining nationwide since 2003 (Newspaper Association of North America 2009b). Conversely, climate change may be causing fire size to increase over time (Westerling et al. 2006). Second, we used a binary variable (SON) that took a value of 1 if a fire started in September, October, or November, and 0 otherwise. We chose this variable because these three months are the busiest in the news cycle (Newspaper Association of North America 2009a); therefore, fire stories would be more likely to be displaced. In addition, in most parts of the country, fires burning during the cooler fall months may be smaller. However, in California, fall is peak fire season. To accommodate different fire seasons, we used SON as an instrument and we also interacted it with a dummy variable denoting fires that ignited in Forest Service Region 5 (all Region 5 fires in our data set are in California). 
All instruments are independent of suppression costs and represent different sources of variation in newspaper coverage and fire size. We limited our instruments to those described, because a parsimonious instrument list reduces the possibility of biased coefficient estimates (Angrist and Krueger 2001).

Our use of 2SLS is only appropriate if one or more variables in our model are codertermined. Therefore, we used a Hausman test (Hausman 1978) to test whether newspaper coverage and fire size were individually and jointly codetermined with suppression costs.

\section{Results}

Of the variables included in the original Gebert et al. (2007) model, all retain their original signs, although some are no longer significant (Table 4). The loss of significance in some cases may be because of the inclusion of the newspaper coverage and political-influence variables, which captured variation previously explained by those other variables, or it may be because we treated wildfire size as endogenous.

The only newspaper coverage variable that was significant was STORY_250 K, which is an instrumented dummy variable that takes on a value of 1 if any newspaper stories were published about a wildfire in the nearest city with a population over 250,000 and 0 otherwise. This simple binary variable had better explanatory power than any of the variables that described the number, length, or prominence of stories. Consistent with our theoretical model, newspaper coverage increased suppression costs. This effect is both statistically and economically significant. Among those fires that had newspaper coverage (101), STORY_250 K increased per-acre suppression costs by an average of $\$ 1,828$.

Of all the political-influence variables evaluated, only the years in office of the member of Congress whose district the wildfire started in was significant (HOUSE_YEARS). As with the effect of newspaper coverage, the effect of HOUSE_YEARS on suppression costs is economically as well as statistically significant. For our sample, an additional year in office increases average per-acre suppression costs by $\$ 16$. It is interesting that none of the variables describing the political influence of members of the Senate were significant. This is perhaps a reflection of the smaller districts and more local focus of House members as compared to the statewide mandate of Senators. ${ }^{8}$ Finally, we reiterate that the years of experience is merely a proxy for some unmeasured (and endogenous) political-influence variable (a latent variable) But the statistical significance of its candidate instrument has a coefficient whose effect is significantly different from zero at $1 \%$ significance, indicating that the latent endogenous variable is a significant explainer of suppression costs in our sample (Angrist and Krueger 2001).

The Hausman test showed that STORY_250 K $(p=.02)$ and SIZE $(p=.11)$ were individually and jointly $(p=.05)$ endogenous. This finding justifies our use of the instrumental variables method of 2SLS. In addition, we found that all four instruments explained a significant portion of the variation in both STORY_250 K and fire size during the first stage ${ }^{9}$ of the 2SLS estimation (Table 5).

In the first-stage STORY_250 K equation, the coefficient on DIST_250 K is negative and highly significant, which indicates that the farther a newspaper is from a fire, the less likely the newspaper is to cover it. In the first-stage SIZE equation, the DIST_250 K coefficient is positive and significant. This may be because fires near 
Table 4. Two-stage least-squares regression results for variables hypothesized to influence the natural logarithm of per acre wildfire suppression costs $(n=444)$

\begin{tabular}{lccc}
\hline Variable & Coefficient & Standard error & $p$ value \\
\hline C & 4.984 & 1.136 & .000 \\
Cosine of aspect & -0.302 & 0.098 & .002 \\
Sine of aspect & -0.054 & 0.106 & .611 \\
Slope & 0.003 & 0.003 & .283 \\
Elevation & 0.000 & 0.000 & .113 \\
Timber ignition point & 0.362 & 0.250 & .148 \\
Grass ignition point & -0.135 & 0.306 & .659 \\
Brush ignition point & -0.246 & 0.389 & .527 \\
Slash ignition point & 0.062 & 0.342 & .856 \\
FIL2 & 0.850 & 0.388 & .029 \\
FIL3 & 1.094 & 0.397 & .006 \\
FIL4 & 0.764 & 0.442 & .084 \\
FIL5 & 1.319 & 0.470 & .005 \\
FIL6 & 1.423 & 0.480 & .003 \\
LOG(DIST_ALL) & 0.130 & 0.190 & .495 \\
LOG(House value 5 miles) & 0.008 & 0.012 & .531 \\
LOG(House value 20 miles) & 0.019 & 0.015 & .207 \\
Wilderness fire & 0.730 & 0.842 & .386 \\
IRA & 1.340 & 0.660 & .043 \\
SDA & -1.190 & 1.576 & .451 \\
(Wilderness)*(DIST_ALL) & -0.397 & 0.313 & .205 \\
(IRA)*(DIST_ALL) & -0.445 & 0.249 & .074 \\
(SDA)*(DIST_ALL) & 0.591 & 0.594 & .320 \\
REG_2 & -0.544 & 0.321 & .091 \\
REG_3 & -1.039 & 0.330 & .002 \\
REG_4 & -0.227 & 0.259 & .381 \\
REG_5 & 0.186 & 0.296 & .530 \\
REG_6 & 0.369 & 0.410 & .369 \\
ERC & 0.021 & 0.006 & .001 \\
LOG(Fire size) & -0.472 & 0.185 & .011 \\
HOUSE_YEARS & 0.029 & 0.010 & $.004^{*}$ \\
STORY_250 K & 2.229 & 0.839 & $.008^{*}$ \\
$R$-squared & 0.377 & & \\
\hline & & & \\
\hline
\end{tabular}

Note. Using a Wald test, the probability that the coefficients on HOUSE_YEARS and STORY_250 K are jointly zero is .0007.

large cities are suppressed more aggressively or firefighting resources are more readily available and therefore these fires tend to be smaller than fires farther away from large cities. The coefficients on YEAR confirmed our hypotheses that newspaper coverage is declining over time and that fire size is increasing. Similarly, the coefficients on SON confirm that wildfires are less likely to receive coverage in September, October, or November compared to other months, and that wildfires are smaller during these months. The exception is California. The interaction 
Table 5. Coefficients and $p$ values for the four variables used as instruments in the first stage of the two-stage least-squares estimation

\begin{tabular}{lccccr}
\hline & \multicolumn{2}{c}{ STORY_250 } & & \multicolumn{2}{c}{ SIZE } \\
\cline { 2 - 3 } \cline { 5 - 6 } Instrument & Coefficient & $p$ value & & Coefficient & $p$ value \\
\hline DIST_250 K & -0.0008 & .0002 & & 0.0024 & .0318 \\
YEAR & -0.0312 & .0614 & & 0.1866 & .0270 \\
SON & -0.1240 & .0492 & & -0.9824 & .0025 \\
SON $*$ REG5 & 0.0471 & .6362 & & 1.3125 & .0092 \\
$R$-squared & 0.312 & & 0.181 & \\
\hline
\end{tabular}

between Region 5 and SON is positive and significant, which indicates that fires are larger during these months compared to other months in California.

The magnitude of the effect of newspaper coverage on wildfire suppression costs may raise eyebrows: Could newspaper coverage really be that influential? One possible source of bias could be accounting for newspaper coverage with a binary variable. Angrist and Imbens (1995) described how a binary variable coefficient estimate could be upwardly biased if the true effect were not binary. However, we have no a priori reason for assuming that newspaper coverage is either binary or continuous. Therefore, we represented newspaper coverage in the manner that optimized model fit.

Newspaper coverage was also significant if we represented it continuously (number of stories), but the model's explanatory power declined somewhat. We could not directly compare the magnitude of the coefficient on newspaper coverage when it was represented continuously to when it was represented discretely. However, we did compare the predicted costs that the two models separately produce, as a way of assessing how much newspaper coverage increased suppression costs. When represented discretely, newspaper coverage increased suppression costs $55 \%$ across the whole sample, whereas if newspaper coverage was represented continuously, suppression costs increased by $40 \%$. Although this comparison is not a formal test, it does suggest that if the coefficient on STORY_250 K is biased, then the level of bias is probably modest.

One other possible source of bias could be one or more omitted variables. In particular, if newspaper coverage were just a proxy for a large, damaging wildfire, then our results would be misleading. However, we do not believe this is the case for a number of reasons. First, both wildfire size and values at risk are among the model regressors. Second, the effect of wildfire size on per-acre suppression costs is negative, whereas the effect of newspaper coverage is positive. Third, the number of stories in the nearest city with a population over 250,000 and housing values at risk are uncorrelated (correlation coefficient of 0.01). Fourth, if newspaper coverage were simply a proxy for values at risk, we would expect newspaper coverage in smaller cities to also influence suppression costs. Indeed, as smaller cities are on average closer to the wildfires in our sample, and smaller newspapers tend to have a more local focus, we would expect coverage in smaller cities to be more correlated with values at risk. However, we found that newspaper coverage in cities with a population of less than 250,000 had no effect on wildfire costs. For all these reasons, 
we believe it is reasonable to interpret the coefficient on our binary variable as the effect of any newspaper coverage on per acre suppression cost of wildfire.

However, as with any regression model, the coefficient on STORY_250 K is a point estimate. The $95 \%$ confidence bounds on the coefficient do not include zero, but do go as low as 0.585 , which corresponds to a total rise in suppression costs across the entire sample of $21 \%$. For the purposes of the article, while the order of magnitude of its impact is informative, the precise size of the effect of newspaper coverage on suppression costs is of secondary importance. Our purpose in studying the effect of newspaper coverage and political influence on suppression costs was to demonstrate the existence of costs solely borne by fire managers. This we have done. In addition, we have shown that manager costs are sufficiently large that it is worthwhile developing policy instruments to reduce them.

\section{Policy Remedies}

Our theoretical model, supported by our empirical results, suggests that managers increase suppression spending in response to newspaper coverage and political pressure because they are concerned about the personal costs of adverse wildfire outcomes. Therefore, one approach to reducing suppression costs would be to implement fire management policies that reduce these personal costs.

A potential mechanism for reducing these personal costs could be to partially or fully indemnify fire managers from the consequences of their wildfire-suppression decisions. Currently, fire managers cannot be held personally liable for their actions if they are acting within the scope of their duties, even if they are acting negligently. ${ }^{10}$ However, if they are found to be acting beyond the scope of their duties, they can be personally sued.

Indemnifying managers against the consequences of their action may seem like a peculiar way of reducing costs. After all, the government would be accepting additional legal liability. However, fire managers are in a unique position. Their work environment is highly charged and uncertain. In addition, they have access to millions of dollars, which they can use to reduce their perceived personal liabilities. And although some fire managers have been sued, this is not common. Setting aside issues of liability, the fact that there is a nonzero probability of this sort of adverse outcome may be enough of an incentive for fire managers to use suppression resources that unproductively increase costs.

Another way to help managers resist media and political pressure would be to adopt some guidelines about when it is appropriate not to suppress wildfires as aggressively as possible. For example, if weather conditions exceed some threshold, then aerial resources should only be used in exceptional circumstances. These sorts of hypothetical guidelines could provide managers with the necessary cover to resist pressure to use expensive resources when they would be unlikely to have a significant effect on wildfire damages. Such guidelines would also shift some of the liability from the manager to the agency's leaders. This would provide managers with cover from internal criticism: They were following guidelines approved by the agency.

\section{Discussion}

Our results suggest that newspaper coverage and political pressure increase wildfire suppression costs, which supports our hypothesis that concern about adverse 
wildfire outcomes is a significant determinant of suppression costs. Clearly, neither newspaper coverage nor political influence can or should be manipulated to reduce suppression costs. However, our results suggest that if policies are put in place that reduce managers' concerns about the personal costs of wildfire-suppression decisions, then suppression costs could be substantially reduced. Furthermore, given that the policy remedies we suggest could be adopted at relatively little cost (guidelines on when not to aggressively suppress wildfires, for example), it is possible that reducing the personal costs of managers may be a more cost-effective way of reducing suppression costs than biophysical approaches such as fuel management.

However, when considering changes in policies or guidelines to reduce the personal costs of adverse wildland fire outcomes, it is worth considering whether public land management agencies, politicians, and the general public are willing to accept the consequences of reduced suppression expenditures. In the abstract, few would argue the need to balance the costs and benefits of wildfire suppression. However, how many people would find it palatable to let someone's house burn down for economic reasons? Concern about rising suppression expenditures seems to fade as homes are being evacuated and smoke fills the air, with calls to save money being replaced by calls to bring in more resources.

\section{Notes}

1. Within a fire season, which is the focus of this article, presuppression is fixed, but prior to the start of a fire season presuppression is variable.

2. Expenditures were obtained from all federal land management agencies with suppression responsibility, including the USFS and four Department of the Interior agencies (National Park Service, Fish and Wildlife Service, Bureau of Indian Affairs, and Bureau of Land Management). State or local expenditures on the fires were not collected due to the difficulties of obtaining this information. By restricting the analysis to fires under the protection responsibility of the USFS or fires where the majority of the acres were USFS, the impact of not obtaining state/local costs is lessened (see Gebert et al., 2007).

3. Distance was measured from the fire's ignition point.

4. We used the Newsbank Database and also searched the databases of individual newspapers.

5. Other forms of media coverage may be correlated with newspaper coverage, so our results may include the effect of other media coverage. However, from a policy point of view, this is not a major concern. Newspaper coverage cannot be directly manipulated. Instead, policy instruments (see Policy Remedies section) will work by reducing the effect of non-biophysical variables on fire managers, and it is difficult to think of a policy instrument so specific that it would reduce the effect of newspaper coverage and not other types of media coverage.

6. An instrument is used to explain variation in an endogenous variable (fire size and newspaper coverage, in our case) during the first stage of a 2SLS analysis. In the first stage, independent variables (elevation and fuel type, for example) plus instruments are used to explain variation in the endogenous variables. The predicted values from the first stage are used in the second stage, in which independent variables and endogenous variables (but not instruments) are used to explain variation in the dependent variable (wildfire suppression costs in our case). For more details, see an econometric textbook such as W. H. Greene (2000).

7. In conventional regression analysis, causation is assumed to flow from the independent variables to the dependent variable. In a situation like ours, where causality flows in both directions, more sophisticated statistical techniques are required to separate the effects. One such technique is 2 SLS.

8. Some sparsely populated states, such as Montana and Wyoming, only have one member of Congress for the entire state. To determine whether at large members of Congress are 
less influential than members with smaller districts, we created a dummy variable for states with just one member of Congress and interacted it with HOUSE_YEARS. This interaction was not statistically significant, which suggests that at-large members of Congress are as influential as other members.

9. In the first stage of 2SLS, all the independent variables (including instruments) are separately regressed against each endogenous variable.

10. The exception is a Bivens Action, which, in contrast to a tort action, has a constitutional basis. However, Bivens Actions against fire managers are extremely rare, and although government employees cannot be excused liability, the government can pay any judgments against an employee.

\section{References}

Abt, K. L., J. P. Prestemon, and K. M. Gebert. 2009. Wildfire suppression cost forecasts for the US Forest Service. J. For. 107:173-178.

Angrist, J. D., and G. W. Imbens. 1995. Two-stage least squares estimation of average causal effects in models with variable treatment intensity. J. Am. Stat. Assoc. 90:431-442.

Angrist, J. D., and A. B. Krueger. 2001. Instrumental variables and the search for identification: From supply and demand to natural experiments. J. Econ. Perspect. 15:69-85.

Arno, S. F., and J. K. Brown. 1991. Overcoming the paradox in managing wildland fire. West. Wildlands 17:40-46.

Bengston, D. N., T. J. Webb, and D. P. Fan. 2004. Shifting forest value orientations in the United States, 1980-2001: A computer content analysis. Environ. Values 13:373-392.

Bond, J., and R. Kirshenbaum. 1998. Under the radar: Talking to today's cynical consumer. New York: John Wiley \& Sons.

Calkin, D. E., K. M. Gebert, J. G. Jones, and R. P. Neilson. 2005. Forest Service large fire area burned and suppression expenditure trends, 1970-2002. J. For. 103:179-183.

Canton-Thompson, J., B. Thompson, K. M. Gebert, D. E. Calkin, G. H. Donovan, and G. Jones. 2006. Factors affecting fire suppression costs as identified by incident management teams. RN-RMRS-030. Fort Collins, CO: Rocky Mountain Research Station.

Collins, B. M., P. N. Omi, and P. L. Chapman. 2006. Regional relationships between climate and wildfire-burned area in the Interior West, U.S.A. Can. J. For. Res. 36:699-709.

Dennis, E. E., and J. C. Merrill. 1996. Media debates: Issues in mass communication. White Plains, NY: Longman.

Donovan, G. H., and T. C. Brown. 2007. Be careful what you wish for: The legacy of Smokey Bear. Front. Ecol. Environ. 5:73-79.

Donovan, G. H., P. Noordijk, and V. Radeloff. 2004. Estimating the impact of proximity of houses on wildfire suppression costs in Oregon and Washington. Paper presented at 2nd Symposium on Fire Economics, Planning and Policy: A Global View, Cordoba, Spain, 19-22 April.

Donovan, G. H., and D. B. Rideout. 2003. A reformulation of the cost plus net value change (C + NVC) model of wildfire economics. For. Sci. 49:318-323.

Fan, D. P. 1988. Predictions of public opinion from the mass media: Computer content analysis and mathematical modeling. New York: Greenwood Press.

Gebert, K. M., D. E. Calkin, and J. Yoder. 2007. Estimating suppression expenditures for individual large wildland fires. Western J. Appl. For. 22:188-196.

Greene, W. H. 2000. Econometric analysis, 4th ed. Upper Saddle River, NJ: Prentice Hall.

Hausman, J. A. 1978. Specification tests in econometrics. Econometrica 46:1251-1271.

Kahneman, D. A., and A. Tversky. 1979. Prospect theory, an analysis of decision under risk. Econometrica 47:263-291.

Kasperson, R. E., O. Renn, P. Slovic, H. S. Brown, J. Emel, R. Goble, J. X. Kasperson, and S. Ratick. 1988. The social amplification of risk: A conceptual framework. Risk Anal. 8: $177-187$. 
Kitzberger, T., P. M. Brown, E. K. Heyerdahl, T. W. Swetnam, and T. T. Veblen. 2007. Contingent Pacific-Atlantic Ocean influence on multicentury synchrony over western North America. Proc. Natl. Acad. Sci. USA 104:543-548.

Knudson, T. 2006. Forest Service budget going up in smoke. http://infoweb.newsbank.com/ iw-search/we/InfoWeb?p_product $=$ AWNB\&p_theme=aggregated5\&p_action $=$ doc\&p_ docid $=11438707 F 91 E 0 A 30 \& p \_$docnum $=2 \&$ p_queryname $=1 \quad$ (accessed 7 September 2009).

Liang, J., D. E. Calkin, K. M. Gebert, T. J., Venn, and R. P. Silverstein. 2008. Spatial factors influencing large wildland fire suppression expenditures. Int. J. Wildland Fire 17:650-659.

Mercer, D. E., J. P. Prestemon, D. T. Butry, and J. M. Pye. 2007. Evaluating alternative prescribed burning policies to reduce net economic damages from wildfire. Am. J. Agric. Econ. 89:63-77.

Mizerski, R. W. 1982. An attribution explanation of the disproportionate influence of unfavorable information. J. Consumer Res. 9:301-310.

National Association of Public Administrators. 2002. Incentives for intergovernmental wildfire hazard mitigation and enhanced local firefighting capabilities. Washington, DC: National Association of Public Administrators.

Newspaper Association of America. 2009a. Nielson online. http://www.naa.org/ TrendsandNumbers/Newspaper-Websites.aspx (accessed 10 November 2009).

Newspaper Association of America. 2009b. Total paid circulation volume. http:// www.naa.org/TrendsandNumbers/Total-Paid-Circulation.aspx (accessed 10 November 2009).

Office of Inspector General. 2006. Audit report: Forest Service large fire suppression costs. Washington, DC: Office of Inspector General.

Prestemon, J. P., K. L. Abt, and K. M. Gebert. 2008. Suppression cost forecasts in advance of wildfire seasons. For. Sci. 54:381-396.

Raude, J., C. Fischler, E. Lukasiewicz, M. Setbon, and A. Flahault. 2004. GPs and the social amplification of BSE-related risk: An empirical study. Health Risk Society 6:173-185.

Shindler, B., B. Steel, and P. List. 1996. Public judgments of adaptive management: A response from forest communities. J. For. 94:5-12.

Vilella-Villa, M., and J. Costa-Font. 2008. Press media reporting effects on risk perceptions and attitiudes towards genetically modified (GM) food. J. Socio-Econ. 37:2095-2106.

Westerling, A. L., H. G. Hidalgo, D. R. Cayan, and T. W. Swetnam. 2006. Warming and earlier spring increase Western U.S. forest wildfire activity. Science 313:940-943. 